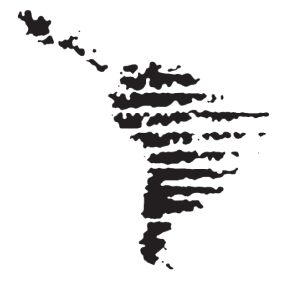

\title{
Hernán Vidal y el aporte de la crítica literaria latinoamericana al proyecto de construcción y defensa de los derechos humanos ${ }^{1}$
}
Hernán Vidal and the Contribution of the Latin American Literary Criticism to the Project of Construction and Defense of Human Rights

\section{Hernán Vidal e a contribuição da crítica literária latino-americana ao projeto de construção e defesa dos direitos humanos}

\section{Gustavo Remedi}

\section{Resumen}

La revisión de la obra crítica y teórica que realizara el investigador y ensayista chileno Hernán Vidal (1937-2015) desde la Universidad de Minnesota sirve de punto de apoyo para explorar un proceso de ida y vuelta. Por un lado, de construcción de una hermenéutica cultural y literaria de los derechos humanos, anclando la primera en los segundos, a fin de realizar una serie de aportes desde la perspectiva de los estudios literarios y culturales latinoamericanos de orientación sociohistórica al propio discurso de promoción y defensa de los derechos humanos en América Latina.

1 Jornadas académicas «Raíces latinoamericanas de los derechos humanos» en la Facultad de Humanidades y Ciencias de la Educación (3-4 de noviembre de 2016).

2 Universidad de la República, Uruguay. 
Palabras clave: Crítica literaria, derechos humanos, América Latina, persona, vida bruta.

\begin{abstract}
The review of the theoretical and critical work the Chilean researcher and essayist Hernán Vidal (1937-2015) carried out from the University of Minnesota serves as a point of support to explore a two-way process. It is a process of construction of a cultural and literary hermeneutics of human rights, anchoring the hermeneutics to rights, in order to carry out a series of contributions from the perspective of the Latin American literary and cultural studies with socio-historical orientation to the own discourse of promotion and defense of human rights in Latin America.
\end{abstract}

Keywords: Literary criticism, human rights, Latin America, person, brute life.

\title{
Resumo
}

Revendo o trabalho crítico e teórico realizado pelo pesquisador e ensaísta chileno Hernán Vidal (1937-2015) desde a Universidade de Minnesota, serve como um suporte para explorar um processo de vai e vem. Por um lado, a construção de uma hermenêutica cultural e literária dos direitos humanos, ligando a primeiro com a segunda, para realizar uma série de contribuições a partir da perspectiva dos estudos literários e culturais latinoamericanos de orientação sócio histórico ao discurso próprio de promoção e defesa dos direitos humanos na América Latina.

Palavras-chave: Crítica literária, direitos humanos, América Latina, pessoa, vida dura.

A partir del repaso de algunos trabajos de Hernán Vidal, intentamos aquí explicar los planteamientos de este investigador chileno en relación, por un lado, con la circunstancia histórica latinoamericana de fines del siglo XX y las movilizaciones en favor de los DDHH, y por otro, los estudios de la cultura y la literatura latinoamericanas de orientación sociohistórica.

El objetivo es compartir el proceso de construcción de una hermenéutica cultural - y literaria - de los derechos humanos de parte de Hernán Vidal, así como realzar algunos de sus aportes teóricos. Primero, su énfasis en la categoría dramática de "persona" - máscara - atada a la de la vida como "escenario" lleno de posibilidades y potencias, es decir, en vez de vida desnuda, vida (in)vestida con la máscara (la personalidad) y personaje que cada cual decide vivir (Vidal, 1987). 
Segundo, apoyándose en Agamben, su preferencia por el concepto de vida bruta al de vida desnuda "que no capta la dimensión salvajemente disciplinaria del concepto" (Vidal, 2000, p. 312) para referirse a la vida humana que no está solo desnuda, sino que ha sido despojada, marcada y contrahecha brutalmente, y aludir a "la aniquilación de la dignidad humana" como resultado de las medidas del poder para perpetuarse, borrando, cuando precisa, la frontera entre bios (la persona humana) y zoé (la humanidad reducida a animalidad) (Vidal, 2000). Tercero, su interés por relacionar categorías y procedimientos de la práctica de la crítica literaria con los de "verdad jurídica" - en un afán por responder tanto al problema de la verdad sin justicia, como a las tendencias nihilistas y escépticas posmodernas- (Vidal, 1994) y también con conceptos provenientes de la ley internacional de derechos humanos como jus cogens (que refiere a normas sagradas, inviolables) y erga omnes: el respeto de todos los derechos de todos, por todos (Vidal, 2014).

Hacia la década de los 70, la crítica literaria "normal" o prevalente se ocupaba del estudio de un canon definido por criterios fundamentalmente academicistas y "belleletrísticos" y los abordaba desde acercamientos biografistas, estilísticos, estructuralistas y tecnicistas en boga. Se buscaba, de este modo, producir conocimiento acerca de un autor o autora, su pensamiento, su sensibilidad y formas de expresión, así como acerca de la calidad de las "grandes obras" - o las obras canónicas- y las innovaciones (técnicas) de las nuevas obras, de algunas a veces relacionándolas con su contexto, las creaciones previas - en los casos del estudio de los géneros o de los estudios genéticos-, o el resto del sistema literario.

Contra este telón de fondo, los aportes de Vidal se enmarcan, primero, dentro de un enfoque de crítica socio-histórica, ya asentada en el contexto latinoamericano, que busca no perder de vista el papel de la institución literaria dentro del proceso social, en la medida en que la literatura es concebida como una forma de mediación ideológica, de modelización del mundo, de construcción de emociones, afectividades y sensibilidades (de "educación sentimental"), y finalmente, de comportamientos (Vidal, 1985), en suma, un terreno adonde se traslada, se pone en juego y también se dirime el conflicto social.

Segundo, en la medida en que la literatura se nutre y existe en medio de una red discursiva y práctica, Vidal recurre forzosamente a la ampliación del objeto de la crítica literaria, lo que lo conduce en la dirección de los estudios culturales latinoamericanos, y que si bien no se originan de los británicos, como él mismo aclara (Vidal, 2001), sí se asemejan más a estos en su sustento histórico-materialista y su vocación política, que a los estadounidenses (Del Sarto, Ríos y Trigo, 2005; Jameson, 2008). 
En "La Declaración de Principios de la Junta Militar chilena como sistema literario. La lucha antifascista y el cuerpo humano", un trabajo publicado originalmente en inglés en Social Text en 1979 y luego publicado en castellano en 1983, Vidal lo explica así:

La conveniencia de considerar el texto de la Declaración de Principios de la Junta Militar de 1974 como eje de un sistema literario está en su utilidad como instrumento problematizador, tanto de la literatura de la resistencia como de la filofascista. ... esta productividad surge de la noción de matrices ideológicas manifestadas metafóricamente. Con ellas se invierte la orientación exclusivista de muchas tendencias críticas intratextuales. Mientras éstas consideran el uso de conceptos extraliterarios como una intromisión indeseable he propuesto un tipo de lectura que reconoce y explora elementos literarios en discursos ajenos a la construcción de mundos ficticios [cursivas añadidas] (Vidal, 1983, p. 62).

Buscando aproximarse a las formas ideológicas que intervienen -ya sea favoreciéndolos, ya bloquéandolos- en los procesos de emancipación, "la crítica literaria no se restringe a una de sus partes" - la literatura de ficción- sino que "se instala en el centro de otros discursos para observar cómo se alimentan entre sí" (Vidal, 1983, p. 63).

Concuerda en que a diferencia de otros discursos - religiosos, científicos, legales - la literatura pone énfasis en una "convención representativa antropocéntrica. ... Las temáticas, símbolos, metáforas, motivos y técnicas discursivas que la literatura ha acumulado ... hacen de la dimensión sensual y emocional del trabajo humano el foco de su representación” (Vidal, 1983, p. 44).

Sin embargo, nos recuerda, esto no es monopolio exclusivo de la literatura de ficción, sino que se trata de "una cuestión de grado". Todo discurso es siempre poético, moviliza una serie de motivos, metáforas y recursos literarios, y está basado sobre "una matriz de relaciones metafóricas constituidas de manera conciente e inconciente" naturalizadas -invisibilizadas - que sirven para imaginar, representar y comunicar realidades complejas. Luego, es tarea de "una lectura literaria detectar y magnificar las resonancias antropocéntricas y sensuales de las metáforas que lo sustentan" (Vidal, 1983, p. 44).

Tercero, el trabajo de Vidal se vincula a una forma de entender la práctica del crítico latinoamericano como parte de un proceso de construcción social 
y transformación de la realidad: razón por la cual la literatura, primero, fue institucionalizada e instrumentalizada por las elites que construyeron el Estado nacional, y que se halla en la base de la razón de su utilización y promoción en la actualidad de parte del Estado y de la sociedad civil como forma de construcción de ciudadanía, de crítica social, de renegociación del sentido de la cultura nacional: de construcción de sensibilidades, mentalidades y comportamientos adecuados al modo de producción y vida social que se desea implementar (ya mantener, ya transformar).

En el caso de Vidal, esa construcción social y esa transformación de la realidad está orientada por un propósito particular: la utopía de la realización de la integridad material y espiritual de las personas, de su bienestar espiritual y material — todos los derechos, de todas la personas sin distinciones (erga omnes)—, según está articulado por el discurso de los derechos humanos; discurso que hacen suyo y esgrimen las organizaciones y movilizaciones sociales populares, usualmente disputándoselo al poder y al manejo que este hace de los mismos.

De este modo, el proyecto de los derechos humanos deviene su sustento hermenéutico.

\section{Fascismo, sistema literario y refundación crítica en América Latina}

En el contexto de las dictaduras de los 70, el referido ensayo "La Declaración de Principios de la Junta Militar chilena como sistema literario. La lucha antifascista y el cuerpo humano" impactó en el campo de los estudios literarios latinoamericanos y se volvió piedra de toque (Franco, 1981) de los estudios culturales latinoamericanos.

Su trabajo implicaba dos cosas. Primero, el posicionamiento y asunción del papel de la crítica literaria respecto a esta nueva circunstancia. Pese a no ser del todo novedosa, pues "el mantenimiento relativo de las libertades burguesas" y "la aceptación acrítica de la ideología que representaba a Chile como tierra de sólida tradición democrática" solo habían servido para ocultar una historia de conspiraciones, golpismos, represión y matanzas de grupos trabajadores, Vidal entiende que de todos modos se trata de una experiencia inusitada en su escala y ferocidad que significa una ruptura histórica (Vidal, 1983, p. 43).

Segundo, implicaba ocuparse de un texto - la Declaración de 1974escrito, actuado, transcripto, difundido y traducido a cuatro idiomas, entendido 
como fundacional y matricial de un lenguaje y una sensibilidad inéditos al que el crítico se acerca para develar su literariedad: el sistema de metáforas y otros recursos poéticos sobre el cual está armado funciona y "hace su trabajo" ideológico, sensibilizador, estetizante. A ese sistema opondrá el sistema metafórico de respuesta de la literatura de la resistencia desplegado por las novelas Tejas verdes de Hernán Valdés (1974) y En este lugar sagrado (1977) de Poli Délano.

Aquí, la hermenéutica de Vidal se arma sobre la base de un enfrentamiento político que se traslada al campo discursivo y poiético: de un lado, la Junta Militar, en tanto vértice del nuevo bloque de poder, su discurso aglutinador y la poética de la que se vale, y por otro, la producción simbólica de la movilización anti-fascista - y de los escritores y escritoras, "que mediante su literatura buscan construir una comprensión y una sensibilidad democrática" - convirtiendo este esfuerzo colectivo (en tanto proviene de quienes escriben y está destinado al conjunto social) en anclaje social, soporte material y marco de referencia ético de la labor crítica.

Para Vidal, el quiebre que significó la dictadura es algo que la intelectualidad -y los escritores - 'deberán[n] digerir de manera analítica, testimonial y poética' (Vidal, 1983). La misión de los escritores y escritoras consistirá en elaborar "una conciencia y una sensibilidad del modo en que los chilenos que adhieren al movimiento popular se pensarán y se sentirán a sí mismos ... en el momento de enfrentar las tareas que tienen por delante" (Vidal, 1983, p. 42).

La literatura deviene un instrumento cognitivo y dador de significados que incluye la educación de las emociones, los afectos y los sentires para este nuevo momento (es decir, instrumento de construcción estética). Construye situaciones, arquetipificaciones y máscaras sociales literarias ofrecidas como formas de comprender la circunstancia y las posibilidades de sentimiento, de identificación, de actuación. La crítica literaria hace su parte al 'identificar y meditar sobre las tendencias actuales' contrapuestas (Vidal, 1983, p. 43) de elaboración simbólica, poética, modelizante, estetizante, subjetivante. Quien investiga, cada docente, tiene el llamado de intervenir y aportar su saber y experiencia en el análisis y la crítica textual, a la develación de estos sistemas metafóricos y poéticas en juego, y la transformación de textos velados, "constitutivamente deficientes' e incluso 'concebidos para la dominación' en lecturas para la emancipación mediante una 'hermenéutica emancipadora'” (Vidal, 1994, p. 55).

En cuanto a los aspectos sustantivos, Vidal reconstruye el sistema metafórico desplegado por la Declaración que descubre organizada en torno a un 
discurso mítico que pone el énfasis en la redención espiritual frente a un mundo corrompido por la materialidad, que hunde sus raíces en el escolasticismo medieval, la Reconquista y la Conquista de América, apareado contradictoriamente con una ideología de gestión técnica-tecnocrática-tecnológica, post-política. La nación es imaginada como una casa o mansión que debe reconstruirse, una fortaleza o bastión que debe ser salvaguardado y defendido por unos modernos templarios, un Templo de Espiritualidad acechado por distintas clases de materialismos y formas de corrupción espiritual: el marxismo y el consumismo occidental.

Como contracara de una humanidad reducida a su espiritualidad en tránsito hacia una finalidad última designada por Dios, los cuerpos, en tanto lugar de la vida, de necesidad, de trabajo y producción, de gozo, y también de la explotación y la violencia infligida - las personas reducidas a "vida bruta"desaparecen del horizonte discursivo, del mismo modo que detrás de la cegadora luminosidad de la espiritualidad desaparecen la política, los sujetos presos y los cuerpos de las personas asesinadas.

La propuesta poética y estética de la Declaración encuentra su respuesta en el motivo de la visibilización, reafirmación y celebración del cuerpo, de la existencia cotidiana y de la vida, en los textos de Valdés y Délano -incluso del cuerpo mortificado, doliente, hediondo o moribundo de los centros de tortura, los campos de concentración que se esconden en los subsuelos del Templo de la Suprema Espiritualidad.

De este modo, las dos novelas apuntan a la restitución de la integridad espiritual y material de la persona, concepto que está en la base del discurso y la movilización por los derechos humanos, sobre el entendido de que 'la dignificación y el respeto por la materialidad [de la vida humana] hace mejor a la Humanidad' (Verdesio, 2006, p. 353).

\section{Metáforas encarnadas y en movimiento}

El momento experimental del texto de 1979 se transforma en un Seminario Internacional en 1984 sobre Facismo y experiencia literaria, publicado en 1985.

En el Prólogo explica Vidal:

El incentivo para la publicación de los resultados del seminario viene de la urgente necesidad de meditar sobre la iniciación de los difíciles procesos de 
redemocratización que actualmente viven Brasil, Uruguay y Argentina, así como del precedente anterior en la España post-franquista. ... Es preciso recordar que la enseñanza de la literatura española comenzó a tomar auge con la inmigración de distinguidos intelectuales de las España republicana, así como la enseñanza democratizante de las literaturas latinoamericanas en las últimas décadas se ha robustecido con la inmigración causada por los fascismos más recientes ... la enseñanza universitaria de las literaturas hispánicas y lusófonas debiera ser periódicamente revisado según las necesidades culturales impuestas por las grandes coyunturas de la historia en que vivimos. (Vidal, 1985, p. ii)

El interés inicial por confrontar los sistemas metafóricos y las sensibilidades emergentes durante el fascismo le condujo, asimismo, a una investigación a medio camino entre la crítica teatral y la antropología simbólica de "los rituales de protesta" llevados a cabo por la Agrupación de Familiares de Detenidos Desaparecidos a partir de 1973.

En Dar la vida por la vida. Ensayo de antropología simbólica, de 1982, Vidal se interesa por la teatralidad de las acciones públicas, retoma la noción del teatro como un ritual simbólico que conserva y expresa valores comunitarios reprimidos y que él asocia a la posibilidad de construir sobre tales bases otras formas de vida. Explora, también, los símbolos y metáforas que estructuran estos rituales, distintas formas teatrales — tales como el encadenamiento, la romería, la inmolación- y los modos de organización simbólico-discursiva que se configuran (por. ej., una “épica avergonzada de sí misma”). (Remedi, 2014b)

Tres años más tarde, continuó con una línea similar de investigación, esta vez sobre las acciones y el discurso del Movimiento contra la Tortura «Sebastián Acevedo» — título de su libro de 1986-, movimiento que lleva el nombre de un minero que se inmoló frente a la Catedral de la Plaza de la Independencia en reclamo de sus dos hijos desaparecidos.

\section{Más allá de la violencia política: La violencia estructural}

En 1987, Vidal deja en un segundo plano la serie Ideologías y literatura y funda un nuevo proyecto editorial explícitamente titulado Literatura y derechos humanos. El cambio esclareció su agenda que dejaba de ser meramente la lucha antifascista - las poéticas y las estéticas pro y con- y pasaba a ser una lucha 
por la realización - la utopía - de los derechos humanos entendidos como la realización del potencial y la vida plena de las personas en su integridad material y espiritual, vara contra la cual será juzgada toda la actividad práctica y discursiva, muda y verbal, poética y estética.

En un afán por identificar y descifrar las coordenadas simbólico-discursivas que como consecuencia de la dictadura vertebran la cultura nacional, entiende que "las problemáticas humanísticas relativas al estudio y defensa de los derechos humanos debían ser uno de los principales factores a considerar en el proceso de continua canonización de obras, movimientos, corrientes y modelos teóricos" (Vidal, 1987).

La acción combinada de autoritarismo, represión y libre mercado es interpretada por Vidal como un régimen de violación de los derechos humanos estructural y sistémico. La crítica de los derechos humanos trasciende la particularidad del orden dictatorial y su operatividad y validez aspira a grados mayores de universalidad, si bien formulada desde la experiencia concreta de la materialidad latinoamericana.

En todo caso, ya no le desvelaban exclusivamente las víctimas de la violencia más obvia del terror de Estado - personas prisioneras políticas, tortura, asesinatos, desapariciones, exilios-, ahora abarcaba al conjunto de las víctimas del nuevo orden económico, social y cultural: objeto de una violencia no menos cruda y feroz que se expresaba especialmente en la situación de explotación y pobreza de las clases trabajadoras, de las personas desempleados, de sus familias, en las muchas caras y formas del despojo y la violencia - metaforizado por la vida en los barrios marginados-, y también las acciones de resistencia y protesta, tema de Poética de la población marginal (1987).

En respuesta a los paradigmas y proyectos críticos que orientan y subyacen la crítica literaria a lo largo de los siglos XIX y XX (el historicismo, el formalismo, el humanismo liberal, el cientificismo, etc.) que tienen por preocupación o bien el arte en sí o bien una modernización y un modelo de progreso excluyentes, Vidal propone reorganizar el trabajo de construcción del corpus así como la labor exegética y crítica a partir de una preocupación y movilización en defensa de los derechos humanos - todos los derechos, para todas las personas-, lo que supone reelaborar esta problemática en términos literarios y estéticos. También, a la inversa, poner a disposición las herramientas y la experticia de la disciplina para una mejor ideación y realización de los derechos humanos. 


\section{Vida bruta y persona (o vida investida)}

Uno de los propósitos que orientan su travesía crítica es develar la matriz de metáforas y los núcleos simbólicos sobre las que se organizan los textos y mediante los que estos realizan su trabajo estético, ideológico y ético.

Otro es establecer el grado en que ese "trabajo" conduce, efectivamente, a la emancipación; o todo lo contrario, en qué medida necesita intervenir el sujeto crítico sobre la obra de arte para convertir una poética para la dominación o un monumento de "mala fe" en una experiencia de libertad, de conciencia, de cambio y movilización crítica.

Parte del desafío consiste en captar los sistemas metafóricos estructurantes. Vidal se detiene y vuelve una y otra vez sobre las metáforas espaciales recurrentes en los discursos y novelas estudiadas: la casa, la casa vacía, la casa grande, la casa de campo, la villa [Grimaldi]: "los espacios estatales de la demolición ${ }^{3}$ humana" (Vidal, 2000, p. 58). Siguiendo la fenomenología materialista de Merleau Ponty y Bachelard, otro punto de interés para Vidal (2000) es el cuerpo como punto de partida de la experiencia y la cognición, así como el lugar de concreción de la integridad material y espiritual de la vida humana.

A estos efectos recurre al concepto de "persona", concepto dramático que refiere al juego de máscaras que también es central en el discurso de los derechos humanos, por cuanto la persona es el sujeto de derecho, lo que diferencia al zoé del bios (Vidal, 2000, p. 59-60).

La persona sería equivalente a vida investida con el "personaje" que cada cual desea/decide vestir, y que no es solamente uno, ni de una vez y para siempre.

La noción de persona, entonces, presupone un escenario -una circunstancia, un estar-, una investidura, un carácter, cierta manera de pensar, de hablar y de actuar. También, una finalidad (intereses, motivaciones, proyectos) y cursos de acción que deberán sortear una serie de obstáculos y antagonismos, los que a su vez resultarán en distintos conflictos y dramas, resueltos y no resueltos. El desarrollo de una personalidad conlleva así la posibilidad de adoptar todas las máscaras - explorar las potencialidades humanas en toda su amplitud- y en ese

3 Vidal hace notar que las técnicas de tortura no son un resultado exclusivo de los cursos de entrenamiento contrainsurgente en la Escuela de las Américas, sino que eran prácticas establecidas en los centros de detención contra delincuentes comunes, y también contra los sujetos enemigos y prisioneros políticos en épocas muy anteriores. 
proceso crear la máscara propia, que es siempre un devenir. Así, en tanto sujeto de derechos, carente de derechos, creador de derechos, en la persona confluyen y entran en juego posibilidades de sentidos opuestos: por un lado, el signo del deseo y la utopía de la integridad, la indivisibilidad y la plenitud material y espiritual de la vida humana - de su dignidad, sus potencialidades, sus sueños- $y$, por otro, las marcas de un proceso histórico de personas inconclusas, siempre en formación: proceso signado por la carencia, la fractura, la contradicción, la indecidibilidad, la ironía, la negación, la inhabilitación, la irineia, etc. (Remedi, 2014a).

La dictadura primero y el neoliberalismo después son definidos por Vidal en términos de negación de la persona, el desdibujamiento la frontera entre zoé y bios reduciendo la vida a "vida bruta" (Vidal, 2000, p. 59), esto es, el despojo de los seres humanos, la condena a muchos seres humanos a una vida de no-personas. (Otra vez, el término apunta a recuperar un momento anterior a la desnudez como desnudamiento o despojo brutal, del mismo modo que Marx, al referirse a la acumulación originaria expone el proceso doble, previo, de expropiación y desnudamiento que en un solo movimiento produce personas que de ahí en más necesitarán vender su trabajo en el mercado - el proletariado- y otras que, habiéndose hecho de un capital, lo comprarán y lo usarán en su beneficio —el capitalista).

Como hemos resaltado en otra oportunidad, en 2001 Vidal explica así su interés en la noción dramática de persona y su rendimiento para el análisis crítico como punto de apoyo de una hermenéutica en la que hace confluir tres planos: 'una dimensión arqueológica (la búsqueda de antecedentes en la "tradición nacional", usando el sicoanálisis); una dimensión histórica (la conexión de los sucesos simbólicos con el sentido de las estructuras económicas, sociales, políticas e ideológicas, usando el materialismo histórico), y una dimensión utópica (la toma de conciencia del bien deseado y todavía no consolidado como realidad, usando las bases escatológicas de la Teología de la Liberación), y que en conjunto permitirían inquirir si los sistemas simbólicos acumulados ... contribuyen o no al respeto de los Derechos Humanos' (Remedi, 2014, p. 168; Vidal, 2001 p. 51).

\section{Epílogo: Hacia una hermenéutica cultural de los derechos humanos}

La catástrofe moral de las dictaduras y su continuación en el desarrollismo neoliberal post-dictadura conduce a Vidal a reconsiderar los fundamentos últimos del arte y de la crítica desde una perspectiva de los derechos humanos. En su libro Crítica literaria como defensa de los derechos humanos. Cuestión teórica (1994) desarrolla su argumento. 
Primero, recuerda que toda práctica, análisis de algo, interpretación y asignación de sentidos se hace desde una experiencia personal (que puede ser compartida, colectiva), desde una creencia, una proyecto y compromisos "con algo" que es preciso explicitar y que es lo que lo legitima y justifica ante sí y ante otros individuos (Vidal, 1994).

Luego se pregunta: "Ante la crisis de las utopías de los siglos anteriores" porque el futuro también tiene su historia- “¿qué razón ética nos da el derecho a hacer imputaciones interpretativas en que basamos nuestra enseñanza y nuestras publicaciones? ... ¿qué factor objetivo valida nuestra interpretación personal(ista) de los textos, e indirectamente, de las culturas que los originaron?" (Vidal, 1994, p. 13).

Dicha proposición se asienta, además, en una interpelación a que la crítica literaria abandone su reclusión tecno-escolástica - su papel de servidor y escudo de Prósperoy que el trabajo intelectual profesional contribuya a la elucidación y "a la solución de los problemas importantes” de la sociedad y la cultura (Verdesio, 2006, p. 348).

En un intento de desmarcarse de una serie de proyectos sociales y críticos dominantes, tales como la modernización y el desarrollismo capitalistas perpetuadores de la desigualdad, la exclusión y la miseria-, los experimentos revolucionarios del s. XX - que ciertamente fueron un punto de referencia para la crítica, pero que se agotaron-, o las posturas desencantadas y nihilistas que recostadas en las teorías de la posmodernidad se pierden en el texto y se retiran del mundo, propone "una hermenéutica cultural en torno a la problemática de los derechos humanos" (Vidal, 1994, p. 17) a manera de nuevo sustento y encuadre del quehacer crítico.

Aun con sus paradojas, anacronismos y tergiversaciones de las que todos somos concientes (Remedi, 2009; Verdesio, 2006), los derechos humanos ofrecen un marco para juzgar el neo-desarrollismo imperante, y son un objetivo ético capaz de concitar la adhesión y expresar las diferentes subjetividades y sujetos afectados en sus derechos y que son reducidas a no personas por efecto de un desarrollo "con más náufragos que navegantes", como diría Eduardo Galeano.

Por lo demás, se trata de un discurso que existe más allá de las creencias y posicionamientos del sujeto crítico, encarnado en una gama de movilizaciones y actores que apelan a ellos, así como un conjunto de organismos, comisiones, institutos y leyes internacionales existentes — resultado de muchas luchas-, 
todo lo cual deviene un fundamento externo que permite eludir los riesgos del ahistoricismo, el esteticismo y el exceso de personalismo en nuestras decisiones, valoraciones y juicios cuando investigamos y enseñamos.

Como todo discurso histórico, no obstante, los derechos humanos no son un discurso "terminado" sino uno en construcción, siempre en tensión porque es expresión de intereses, momentos y procesos sociales e históricos contradictorios (Quevedo, 1996; Remedi, 2009), lo que supone no solo promover y defender los derechos, sino crear derechos nuevos y nuevos sujetos de derecho, cuestionar incluso algunos derechos, que vienen de otros tiempos.

A través de artefactos literarios -o mediante sus lecturas literarias de distintas clases de textos- el sujeto crítico se instala dentro del espacio social como conciencia crítica y mediadora entre la particularidad del texto y su potencial y provecho para la construcción de personas, investidas con derechos humanos, entendidos estos como evidencia/estadio superior del desarrollo histórico de la conciencia ética de la humanidad (Vidal, 1994). Así, deviene agente dinamizador de un tránsito de la particularidad americana a la universalidad de los derechos de las personas, realizando el significado y valor de la literatura como instrumento constituyente del principio de vida y de humanización (contra el principio de muerte y la deshumanización) (Vidal, 1994).

Segundo, arrebata la literatura monumentalizada y cosificada (vaciadade-contenido) y los sistemas metafóricos que construye, y pone a circular a la razón instrumental - sus usos para el poder y la dominación- y los recupera para una razón emancipadora.

En este punto, Vidal se apoya, pero toma distancia, en Theodor Adorno. Descree del potencial intrínsecamente emancipador del arte y la lectura (Vidal, 1994) puesto que su sentido está socialmente y culturalmente mediado y nos llega como artefacto consumado/cerrado (significado por el poder para el poder).

Por esto Vidal se refiere a la "deficiencia constitutiva" de la literatura/del arte (Vidal, 1994, p. 56) en la medida en que son definidos y asimilados por los discursos dominantes y la lectura también es pautada por la cultura dominante, lo que vuelve necesaria una práctica hermenéutica emancipadora, es decir, orientada por algún proyecto y utopía para que el arte recobre su magia, la literatura su efecto liberador y la crítica un papel en el proceso emancipatorio. 


\section{Referencias}

Del Sarto, A., Ríos, A. y Trigo, A. (2005). Latin American Cultural Studies Reader Durham: Duke University Press.

Franco, J. (1981). "Trends and Priorities for Research on Latin American in the 1980s: Latin American Literature" The Wilson Center Working Papers N. ${ }^{\circ}$ 111 Washington DC: 125-35.

Jameson, F. (2008). The Ideologies of Theory. Londres: Verso.

Quevedo, L. A. (1996). Teoría y crítica de los derechos humanos en la modernidad. En A. Pierini (Ed.), Pensamiento crítico sobre derechos humanos. Buenos Aires: Eudeba.

Remedi, G. (2009). “¿Esqueletos en el ropero? Los Derechos Humanos desde la cultura?" Cuadernos del Claeh 96-97, 31 (1-2), 41-67.

Remedi, G. (2014a). Afterword: Tell Me How It Happened: Unbinding the Discourse on Memory, the Political Crimes of the Recent Past, and Human Rights. En Ana Forcinito, (Ed.), Layers of Memory and the Discourse of Human Rights: Artistic and Testimonial Practices in Latin America and Iberia (pp. 215-230). Hispanic Issues On Line.

Remedi, G. (2014b). Hernán Vidal, crítica teatral y derechos humanos: Inflexiones en el discurso teórico-crítico acerca del teatro de América Latina. Revista Gestos. Teoría y práctica del teatro hispánico, 29(57), 153-173.

Remedi, G. (2015). Latinoamericanismos de fin de siglo: Paradigmas críticos emergentes y reconfiguraciones de una disciplina doblemente territorializada. En G. Remedi (Ed.), Vistas cruzadas. Los estudios de América Latina en EEUU en los 90, vistos desde el Sur. Un diálogo interdisciplinario (pp. 19-74). Montevideo: Zona Editorial/CEIL-FHCE..

Verdesio, G. (2006). Hernán Vidal y los Derechos Humanos: Hacia una reformulación de la teoría y la praxis de los estudios subalternos. En M. Moraña y J. Campos (Eds.), Ideologías y Literatura. Homenaje a Hernán Vidal (pp. 347-360). Pittsburgh: Instituto Internacional de Literatura Iberoamericana.

Vidal, H. (1979). The Politics of the Body: The Chilean Junta and the Anti-Fascist Struggle. Social Text2(Summer), 104-119.https://doi.org/10.2307/466400 
Vidal, H. (1982). Dar la vida por la vida: Agrupación Chilena de Familiares de Detenidos Desaparecidos. Ensayo de antropología simbólica. Minneapolis: Instituto para el Estudio de las Ideologías y la Literatura.

Vidal, H. (1983). La Declaración de Principios de la Junta militar chilena como sistema literario: la lucha antifascista y el cuerpo humano. En N. Larsen (Ed.), The Discourse of Power. Culture, Hegemony and The Authoritarian State in Latin America (pp. 43-66). Minneapolis: Institute for the Study of Ideologies and Literature.

Vidal, H.(1985).Fascismo y experiencia literaria: Reflexiones para una recanonización. Minneapolis: Institute for the Study of Ideologies and Literature.

Vidal, H. (1986). El Movimiento contra la tortura Sebastián Acevedo Derechos Humanos y la producción de símbolos nacionales bajo el fascismo chileno. Minneapolis: Institute for the Study of Ideologies and Literature.

Vidal, H. (1987). Poética de la población marginal. Fundamentos materialistas para una historiografía estética. Serie Literatura y Derechos Humanos N. ${ }^{\circ}$ 1. Minneapolis: Institute for the Study of Ideologies and Literature.

Vidal, H. (1989). Cultura nacional chilena, crítica literaria y derechos humanos. Serie Literatura y Derechos Humanos N. ${ }^{\circ}$. Minneapolis: Institute for the Study of Ideologies and Literature.

Vidal, H. (1994). Crítica literaria como defensa de los derechos humanos. Cuestión teórica. Newark, Delaware: Juan de la Cuesta.

Vidal, H. (1997). Política cultural de la memoria histórica. Derechos humanos y discursos culturales en Chile. Santiago de Chile: Mosquito Editores.

Vidal, H. (2000). Chile: Poética de la tortura política. Santiago de Chile: Mosquito Editores.

Vidal, H. (2001). Estudios culturales: ¿Disciplina ya constituida o agendas convergentes? Nuevo Texto Crítico 13-14(25-28), 247-254.

Vidal, H. (2004). La literatura en la historia de las emancipaciones latinoamericanas. Santiago de Chile, Mosquito Editores.

Vidal, H. (2009) An Aesthetic Approach to Issues of Human Rights. En Ana Forcinito y Fernando Ordóñez (Eds.), Human Rights and Latin American Culture, Hispanic Issues, 4(1), 14-43. 
Vidal, H. (2014). Universal Truth: Juridical Notes for a Cultural Hermeneutics nased on Human Rights. En Ana Forcinito (Ed.), Layers of Memory and the Discourse of Human Rights: Artistic and Testimonial Practices in Latin America and Iberia. Hispanic Issues On Line: 181-187.

Vidal, H. y Jara, R. (Eds.) (1986). Testimonio y literatura. Minneapolis: Institute for the Study of Ideologies and Literature.

Recibido: 21/11/2016

Aceptado: 5/6/2017 